\title{
Preference for anonymity in sperm donation for artificial insemination: an experience from low- resource settings in Nigeria
}

This article was published in the following Dove Press journal:

Patient Preference and Adherence

\section{Euzebus Chinonye \\ Ezugwu ${ }^{1,2}$ \\ George U Eleje E $^{3,4}$ \\ Chukwuemeka A lyoke ${ }^{1,2}$ \\ Sunday G $\mathrm{Mba}^{5}$ \\ Henry C Nnaji ${ }^{2}$ \\ Chukwunonso I \\ Enechukwu ${ }^{4}$ \\ Peter $\mathrm{O} \mathrm{Nkwo}^{1,2}$ \\ 'Department of Obstetrics and Gynecology, Faculty of Medical Sciences, College of Medicine, University of Nigeria, Ittuku Ozalla Campus, Enugu State, Nigeria; ${ }^{2}$ Department of Obstetrics and Gynecology, University of Nigeria Teaching Hospital, Ituku-Ozalla, Enugu State, Nigeria; ${ }^{3}$ Department of Obstetrics and Gynecology, Faculty of Medicine, Nnamdi Azikiwe University, Awka, Anambra State, Nigeria; ${ }^{4}$ Department of Obstetrics and Gynecology, Nnamdi Azikiwe University Teaching Hospital, Nnewi, Anambra State, Nigeria; ${ }^{5}$ Department of Obstetrics and Gynecology, Enugu State University Teaching Hospital, Enugu State, Nigeria}

Correspondence: Euzebus Chinonye Ezugwu

Department of Obstetrics and Gynecology, Faculty of Medical Sciences, College of Medicine, University of Nigeria, Ittuku-Ozalla Campus, PMB 0I I29, Enugu State 40000I, Nigeria Tel +2348037020295

Email euzebus.ezugwu@unn.edu.ng
Objective: Anonymous sperm donation is a common practice in Nigeria with its associated legal and ethical challenges. This study aimed to investigate infertile couples' opinions about issues of sperm donor anonymity and to determine factors that might influence their preferences.

Methods: A cross-sectional, multicentered, questionnaire-based study was conducted among infertile couples attending infertility clinics in three tertiary hospitals in the south-eastern region of Nigeria over a period of 6 months.

Results: A total of 450 infertile couples were recruited consecutively from the three study centers. However, 450 females and 352 males (total=802) participated in the study. The level of awareness of artificial insemination using donor sperm for the management of male infertility among the respondents was $69.2 \%$, while its acceptability rate was $62.7 \%$. The majority of the respondents indicated their preference for secrecy and anonymity in sperm donation. Approximately $84 \%$ of the respondents indicated that the mode of conception should never be disclosed to the donor-conceived child, and $\sim 92 \%$ of them indicated that the identity of the sperm donor should never be revealed to the donor-conceived child. Fear of adverse effect of such disclosure on the child and the possible of rejection of the father in order to seek for the donor were the major reasons for their preference for anonymity.

Conclusion: Although it has been argued that every child has a right to know their genetic parents, the reasons proffered by the respondents for their preference for anonymity cannot be totally ignored. Establishing a regulatory body and enacting laws that will address both the ethical and legal issues associated with gamete donation in the developing world will go a long way in promoting openness and honest communication with donor-conceived children.

Keywords: disclosure, anonymity, artificial insemination, donor sperm, infertile couple, Nigeria

\section{Introduction}

Artificial insemination using donor (AID) sperm is one of the oldest techniques in reproductive medicine ${ }^{1}$ for the management of male infertility due to low sperm count or total absence of spermatozoa in an ejaculate. Male factor infertility is a global problem, solely responsible for $20 \%-30 \%$ of infertility cases. ${ }^{2}$ Reportedly, it accounts for $42.4 \%$ of infertility cases in the south-eastern region of Nigeria. ${ }^{3}$

Donor insemination was first used in clinical practice in England in the late 1930s. ${ }^{4}$ The development of technique for freezing and storage of spermatozoa in the 1940s by a team of scientists led by Chris Polge in Cambridge, England, ${ }^{5}$ further enhanced 
the use of donor sperm for artificial insemination and in vitro fertilization with good outcome. Globally, thousands of people have been born following donor insemination. ${ }^{6}$ The Human Fertilisation and Embryo Authority (HFEA) reports that $\sim 36,000$ donor-conceived children were born between 1992 and 2009 in the UK. ${ }^{7}$

Donor insemination may be known or anonymous. Information sharing in the form of disclosure or secrecy in gamete donation for assisted reproductive technology has been an area of controversy and much debate. ${ }^{8-10}$ Some of the ethical challenges that infertile couples face when considering the use of donor sperm to achieve pregnancy are whether or not to tell the child that he/she was conceived using donated sperm and whether to disclose the identity of the sperm donor to the child or not. ${ }^{11}$ The use of donor sperm for artificial insemination and assisted reproduction in the early days were shrouded in secrecy with donor anonymity being the order of the day in most Western countries. ${ }^{4}$ However, this culture of secrecy has been challenged and is currently changing. ${ }^{9}$ Currently, in many developed countries, nonanonymity in sperm donation seems to be the new trend. Sweden (in 1984) was the first country to make donor nonanonymous. ${ }^{6}$ Up until 1988, the legislation was complete anonymity for donor in Victoria, Australia. ${ }^{12}$ Currently, many developed countries of the world have legislation against donor anonymity. This is based on the principle that the child has a right to know his/her genetic origin ${ }^{12,13}$ and not telling the child violates his/her autonomy. ${ }^{14}$ Proponents have argued that disclosure is part of open and honest communication with children in a home ${ }^{15}$ and should be encouraged. In many developed countries, donor-conceived children have the right upon attaining age of maturity to know the identity of their donor. ${ }^{1}$

In Nigeria, as in many African countries, married couples are usually desperate to have a child. Although a good number of infertile couples in Nigeria may be interested in achieving pregnancy with donor sperm, what is not clear is their willingness to disclose to their child that he/she is a product of AID sperm or the identity of the donor. The study was aimed to investigate infertile couple's opinion about issues of sperm donor anonymity and to determine factors that might influence their choice of disclosure or nondisclosure.

To the best of our knowledge, there are few studies, if any in Nigeria, to determine the infertile couple's disposition toward disclosure of sperm donors to donor-conceived children. It is hoped that the findings of the study will serve as a guide for counseling of affected couples and in policy formulation aimed at addressing some of the ethical and legal challenges associated with gamete donation in the developing world.

\section{Methods}

A questionnaire-based, cross-sectional study among infertile heterozygous couples attending infertility clinic at three government-owned tertiary hospitals, University of Nigeria Teaching Hospital (UNTH), Ituku-Ozalla, Enugu; Enugu State University Teaching Hospital (ESUTH); and Nnamdi Azikiwe University Teaching Hospital (NAUTH), Nnewi, Anambra State, in the south-eastern region of Nigeria was conducted over a 6-month period from 1 January 2016 to 30 June 2016. There are five states that constitute the southeastern region of Nigeria - Abia, Enugu, Ebonyi, Anambra, and Imo with a population of $\sim 16$ million people, predominantly the Igbos.

All infertile couples attending fertility clinic at the three study centers were recruited consecutively after obtaining written informed consent from them to participate in the study. In cases where only one partner/spouse presented at the clinic, the interview was conducted and the spouse was invited for an interview on his or her next follow-up clinic visit.

Based on assumed disclosure rate of $50 \%$, at $95 \%$ CI, $5 \%$ error margin, and $10 \%$ attrition rate, $\sim 450$ infertile couples were interviewed (150 from each study center). Using a pretested interviewer-administered questionnaire, relevant information was obtained from the couples. Data were entered and analyzed using Epi Info statistical software version 17 (Centers for Disease Control and Prevention, Atlanta, GA, USA), and frequency tables were generated for relevant variables. Descriptive and inferential statistics were done. Proportions were compared via the Pearson $\chi^{2}$-test, and relationships were expressed via the odds ratio (OR) and CI. $p$-value of $<0.05$ was considered as statistically significant.

Ethical approval to conduct the study was obtained from the hospital ethics committees of UNTH, ESUTH, and NAUTH.

\section{Results}

A total of 460 couples were recruited consecutively from the three study centers; however, 450 females $(97.8 \%$, $\mathrm{n}=450 / 460)$ and 352 males $(76.5 \%, \mathrm{n}=352 / 460)$ participated in the study. A total of 98 male partners (21.3\%) either declined to participate or could not be reached throughout the period of the study and were, therefore, excluded from the analysis.

The mean age of the male respondents was significantly higher than that of the female respondents $(42.1 \pm 6.7$ vs $32.3 \pm 5.5$ years, $p$-value $<0.001)$. The majority of the respondents were Igbos $(90.8 \%, 728 / 802)$, Christians (99.6\%, 
Table I Sociodemographic characteristics of the respondents

\begin{tabular}{|c|c|c|c|}
\hline Characteristics & $\begin{array}{l}\text { Female } \\
\text { respondents } \\
(\mathrm{n}=\mathbf{4 5 0}), \mathrm{n}(\%)\end{array}$ & $\begin{array}{l}\text { Male } \\
\text { respondents } \\
(\mathrm{n}=352), \mathrm{n}(\%)\end{array}$ & $\begin{array}{l}\text { Total } \\
(n=802), \\
n(\%)\end{array}$ \\
\hline \multicolumn{4}{|l|}{ Age (years) } \\
\hline $20-29$ & I0I (22.5) & $0(0)$ & $95(11.8)$ \\
\hline $30-39$ & $276(61.4)$ & $78(22.2)$ & $343(42.8)$ \\
\hline $40-49$ & $70(15.5)$ & $234(66.5)$ & $318(39.7)$ \\
\hline $50-59$ & $3(0.6)$ & $40(11.3)$ & $46(5.7)$ \\
\hline \multicolumn{4}{|l|}{ Tribe } \\
\hline lgbo & $4 I I(91.3)$ & $317(90.1)$ & $728(90.8)$ \\
\hline Hausa & $6(1.3)$ & $5(1.4)$ & II (I.4) \\
\hline Yoruba & $9(2)$ & $7(2.1)$ & $16(2)$ \\
\hline Others & $24(5.4)$ & $23(6.4)$ & $47(5.8)$ \\
\hline \multicolumn{4}{|l|}{ Religion } \\
\hline Christianity & $447(99.4)$ & $352(100)$ & $799(99.6)$ \\
\hline Islam & $3(0.6)$ & 0 & $3(0.4)$ \\
\hline \multicolumn{4}{|c|}{ Highest educational level } \\
\hline No formal education & $3(0.6)$ & $0(0)$ & $3(0.4)$ \\
\hline Primary & $20(4.4)$ & $7(2.1)$ & $27(3.4)$ \\
\hline Secondary & $158(35.2)$ & $118(33.5)$ & $276(34.4)$ \\
\hline Tertiary & $269(59.8)$ & $227(64.4)$ & $496(61.8)$ \\
\hline
\end{tabular}

$\mathrm{n}=799 / 802$ ), and had attained at least secondary education $(96.2 \%, 772 / 802)$. The mean duration of the couple's infertility prior to the study period was 4.5 years (range $=1-15$ years). These characteristics are shown in Table 1.

Approximately two-third $(69.2 \%, \mathrm{n}=549 / 802)$ of the respondents were aware of the practice of AID sperm for the treatment of male infertility, while approximately one-third of them $(30.8 \%, n=235)$ had never heard of this practice. The awareness rate was significantly higher among the male respondents compared to their female counterpart
(74\% vs $64.3 \%, \mathrm{OR}=0.63 ; \mathrm{CI}=0.47-0.87, p$-value $<0.001)$ This is shown in Table 2.

Majority (50\%) of the respondents learnt about the practice from health talks in hospitals/clinics and from the media (21.2\%). While $\sim 62.7 \%$ of the respondents ( $n=503 / 802$ ) were willing to either accept or allow their wife achieve pregnancy using donor sperm, approximately one-third of the respondents $(32.2 \%, \mathrm{n}=258 / 802)$ were unwilling. Female respondents were two times more likely to accept the use of donor sperm to achieve pregnancy compared to their male counterpart $(70.0 \%$ vs $53.4 \%$; OR=2.02, CI $=1.49-2.73$, $p$-value $<0.01)$. This is shown in Table 2 .

The reason for acceptance of AID sperm among respondents was the desperate desire to achieve pregnancy. Religious belief $(47.7 \%, \mathrm{n}=123 / 258)$ and the feeling that AID was morally wrong $(20.1 \%, n=52 / 258)$ were the major reasons for nonacceptance.

Only $\sim 16.0 \%$ ( $\mathrm{n}=128 / 802)$ of the respondents indicated that parents of donor-conceived children should disclose the mode of conception to the child, mainly to avoid being dishonest (telling lies; 45.3\%) and for fear of the child discovering later in life (39.1\%). This is shown in Table 3.

The majority of the respondents $(84 \%, \mathrm{n}=674 / 802)$ were of the opinion that parents should not disclose the mode of conception to the child. The reasons for their nondisclosure preference were mainly fear that such a disclosure might affect the child adversely, both emotionally and psychologically $(49.3 \%)$, and fear of rejection of the father to seek for the donor (22.4\%). This is shown in Table 4.

Table 2 Distribution of respondents based on their awareness and acceptability rate for AID and willingness to disclosure

\begin{tabular}{|c|c|c|c|c|c|}
\hline Characteristics & $\begin{array}{l}\text { Female } \\
\text { respondents } \\
(n=450), n(\%)\end{array}$ & $\begin{array}{l}\text { Male } \\
\text { respondents } \\
(n=352), n(\%)\end{array}$ & $\begin{array}{l}\text { Total } \\
(n=802)\end{array}$ & OR $(95 \% \mathrm{Cl})$ & $p$-value \\
\hline \multicolumn{6}{|l|}{ Aware of AID } \\
\hline Yes & $289(64.3)$ & $260(74)$ & $549(69.2)$ & $0.63(0.47-0.86)$ & $<0.01$ \\
\hline No & 161 (35.7) & $92(26)$ & $253(30.8)$ & & \\
\hline \multicolumn{6}{|c|}{ Acceptability of donated sperm } \\
\hline Yes & $315(70)$ & $188(53.4)$ & $503(62.7)$ & $2.02(1.49-2.73)$ & $<0.01$ \\
\hline No & $117(26)$ & $|4|(40.1)$ & $258(32.2)$ & & \\
\hline Undecided & $18(4)$ & $23(6.5)$ & $4 I(5.1)$ & & \\
\hline \multicolumn{6}{|c|}{ Should parent disclose mode of conception? } \\
\hline Yes & $79(17.6)$ & $49(14)$ & $128(16.0)$ & $1.32(0.89-1.94)$ & 0.16 \\
\hline No & $371(82.4)$ & $303(86)$ & $674(84.0)$ & & \\
\hline \multicolumn{6}{|c|}{ If yes, at what age? $(n=\mid 28)$} \\
\hline$<18$ years & $22(27.8)$ & $12(24.5)$ & $34(26.6)$ & $1.19(0.53-2.69)$ & 0.68 \\
\hline$\geq 18$ years & $57(72.2)$ & $37(75.5)$ & $94(73.4)$ & & \\
\hline \multicolumn{6}{|c|}{ Should parents disclose the identity of the donor to the child? } \\
\hline Yes & $39(8.6)$ & $25(7.1)$ & $64(8.0)$ & $1.24(0.74-2.09)$ & 0.42 \\
\hline No & $4 I I(9 \mid .4)$ & $327(92.9)$ & $738(92.0)$ & & \\
\hline
\end{tabular}

Abbreviations: AID, artificial insemination using donor; OR, odds ratio. 
Table 3 Distribution of respondents based on reason for supporting disclosure of mode of conception to donor-conceived children

\begin{tabular}{llll}
\hline $\begin{array}{l}\text { Reason for } \\
\text { supporting } \\
\text { disclosure }\end{array}$ & $\begin{array}{l}\text { Female } \\
\text { respondents } \\
(\mathbf{n}=\mathbf{7 9}), \mathbf{n}(\%)\end{array}$ & $\begin{array}{l}\text { Male } \\
\text { respondents } \\
(\mathbf{n = 4 9 )}, \mathbf{n}(\%)\end{array}$ & $\begin{array}{l}\text { Total } \\
(\mathbf{n}=1 \mathbf{2 8}), \\
\mathbf{n}(\%)\end{array}$ \\
\hline $\begin{array}{l}\text { To avoid being } \\
\text { dishonest (telling lies) }\end{array}$ & $42(53.2)$ & $16(32.7)$ & $58(45.3)$ \\
$\begin{array}{l}\text { Fear of the child } \\
\text { discovering later in life }\end{array}$ & $20(25.3)$ & $30(61.2)$ & $50(39.1)$ \\
$\begin{array}{l}\text { The child has a right } \\
\text { to know }\end{array}$ & $17(21.5)$ & $3(6.1)$ & $20(15.6)$ \\
\hline
\end{tabular}

Although a higher proportion of female respondents compared to their male respondents were in support of disclosure, the difference was not statistically significant (17.6\% vs $14 \%$, $\mathrm{OR}=1.32, \mathrm{CI}=0.89-1.94)$. This is shown in Table 2.

Approximately $8 \%(n=64 / 802)$ of the total respondents indicated that parents should disclose the identity of the sperm donor to their donor-conceived child. The majority of them $(92.0 \%, \mathrm{n}=738 / 802)$ indicated that parent should not. This is shown in Table 2.

\section{Discussion}

The rate of awareness of AID sperm for the treatment of male infertility in the south-eastern region of Nigeria was $69.2 \%$. This is greater than the earlier reported figures of $46.6 \%$ in Enugu $^{16}$ and $35.3 \%$ in Yaoundé, Cameroon. ${ }^{17}$ The increased awareness rate seen may be due to the increasing availability of more fertility centers in the region. The activities of these centers may have contributed to the increased level of awareness recorded. However, almost one-third of the respondents had never heard of AID sperm.

The acceptability rate of AID sperm in the study was $62.7 \%$. This is also higher than $43 \%$ earlier reported in Enugu. ${ }^{16}$ Interestingly, female respondents had a significantly higher

Table 4 Distribution of respondents based on reason for supporting nondisclosure of mode of conception to donorconceived children

\begin{tabular}{llll}
\hline $\begin{array}{l}\text { Reasons for } \\
\text { supporting } \\
\text { nondisclosure }\end{array}$ & $\begin{array}{l}\text { Female } \\
\text { respondents } \\
(\mathbf{n}=\mathbf{3 7 I}), \mathbf{n}(\%)\end{array}$ & $\begin{array}{l}\text { Male } \\
\text { respondents } \\
(\mathbf{n}=\mathbf{3 0 3}), \mathbf{n}(\%)\end{array}$ & $\begin{array}{l}\text { Total } \\
(\mathbf{n}=674), \\
\mathbf{n}(\%)\end{array}$ \\
\hline $\begin{array}{l}\text { Disclosure might affect } \\
\text { the child adversely }\end{array}$ & $170(45.8)$ & $162(53.5)$ & $332(49.3)$ \\
$\begin{array}{l}\text { Fear of rejection of the } \\
\text { father to seek for his } \\
\text { biological (donor) father }\end{array}$ & $88(23.7)$ & $63(20.8)$ & $15 \mid(22.4)$ \\
$\begin{array}{l}\text { It is not necessary to tell } \\
\begin{array}{l}\text { The child may lose his } \\
\text { inheritance based on } \\
\text { culture }\end{array}\end{array}$ & $68(18.1)$ & $57(18.8)$ & $102(15.1)$ \\
\hline
\end{tabular}

acceptance rate than their male counterpart. This could be attributed to the desperate desire of women in the region to have a child in order to secure their marriage. In Nigeria as in many African cultures, womanhood is defined by the ability to have a child and the woman is usually blamed for the inability to have a child ${ }^{18}$ and is at risk of abandonment or divorce. ${ }^{19}$ In addition, the fact that the woman contributes to the genetic makeup of the child may have contributed to the higher acceptance rate recorded among them.

Notably, $\sim 84 \%$ of the respondents indicated that parents should not disclose the mode of conception to donorconceived children. Majority of them indicated that such disclosure could harm the child both psychologically and emotionally. Their position seem to agree with some authors who had previously argued that informing a child that he/she was donor conceived could subject the child to social and psychological turmoil, which could be very frustrating, especially if the child want to know more about the sperm donor but cannot. ${ }^{14,20}$ Another reason for supporting nondisclosure by respondents was the fear that the child might reject the father and seek to know the donor. Fear of rejection of the nongenetic father has been documented as a potential factor against disclosure. ${ }^{21}$ It has been reported that parents of donor-conceived children are usually faced with the challenge of whether to tell or not to tell for fear of the impact such disclosure will have on the child's desire to meet their donor $^{9}$ and the subsequent chain of event that might result. In fact, some of the respondents indicated that disclosing to the child that he/she was donor conceived is unnecessary. This position may be a reflection of how male infertility is viewed in Nigeria. In Nigeria and in many other countries, male infertility is regarded as a taboo ${ }^{22}$ and is handled with discretion to protect male dignity. ${ }^{23}$ The fear that once the child is aware, he/she might seek to know the donor, thus exposing the secret. The fear of stigmatization by the society as "not being man enough" and the attempt to protect the man's ego and dignity may have accounted for the disposition toward nondisclosure.

Interesting, approximately nine out of ten respondents indicated that the identity of the sperm donor should not be disclosed to donor-conceived children. This is similar to what was obtainable in many Western countries in the past, where parents preferred gamete donor anonymity and were even encouraged to maintain secrecy. Interestingly, this is changing. Evidence suggests that parental attitude is moving toward openness and donor nonanonymity in the developed world. ${ }^{1,24,25}$ Countries such as Austria, Finland, Iceland, the Netherlands, Switzerland, UK, New Zealand, and the Australian states of New South Wales, Victoria, and Western 
Australia have since removed donor anonymity. ${ }^{4,23,26}$ In these countries, donor-conceived children have the right upon attaining the age of maturity, usually 18 years, to know the identity of their sperm donor.

The proponents of sperm donor nonanonymity argue that the child has a right to know his/her genetic origin. Article 7 of the United Nations Convention on the Rights of the Child (1989) states that the child has a right to know one's parents, ${ }^{27}$ thus knowing one's biological origins is a basic human right. Recently, it has been argued that with the increasing participation of many in the international genetic genealogy database and the increasing availability of directto-consumer genetic testing and diagnosis, complete anonymity in gamete donation cannot be guaranteed, especially in the developed world, and this has challenged the wisdom in gamete donor anonymity. ${ }^{6}$ Although, direct-to-consumer genetic diagnosis and genetic database are currently unavailable in Nigeria, it is important to note that the world is fast becoming a global village.

It is interesting to note that contrary to donor nonanonymity advocated in Western countries, majority of the infertile couples in the south-eastern region of Nigeria indicated their preference for donor anonymity. This preference may be as a result of the absence of legislation in Nigeria addressing the legal issues involved in gamete (sperm) donation. In countries where donor nonanonymity is practiced, there are usually regulatory bodies and legislations guiding gamete donation and its use in ART. In the UK, sperm donors do not have any legal claim to the child and are also protected from any legal responsibility to the child. ${ }^{4}$ In Nigeria, there is no regulatory body or legislation guiding gamete donation and its use in assisted reproduction. The absence of legislation to protect the infertile couples and the fear of the possibility of a legal tussle in the future between the infertile couple and the sperm donor on who is the legally recognized father might have influenced their support for secrecy and their choice for nondisclosure. In addition, the absence of legislation guiding gamete donation in Nigeria leaves sperm donors legally unprotected. With the prevalent economic challenges in Nigeria, a donor-conceived child in future may make legal claim for financial support from the donor if identified. This legislative gap can influence the donor's choice for anonymity and willingness to donate sperm in Nigeria and in many countries of the developing world.

\section{Conclusion/recommendations}

The majority of the respondents indicated that parents should disclose neither the mode of conception nor the identity of the donor to donor-conceived children, contrary to the current trend of nonanonymity in the Western world. Their position probably may have been influenced by the absence of legal and ethical guidelines for assisted reproduction in Nigeria as in many developing countries. With the increasing availability of infertility centers in developing countries including Nigeria and increasing demand for their services by infertile couples in the region, there is a need to establish regulatory bodies as is obtainable in the Western world to regulate the activities of fertility experts. There is also an urgent need to enact laws and legislations in Nigeria and in many developing world that would protect the affected couples, gamete donors, and donor-conceived children. By an act of legislation, sperm donors should have no legal claim over donor-conceived child as is obtainable in the UK. In addition, sperm donors themselves should be protected by law from any responsibility to the child should their identity be disclosed. There is also the need for cultural reorientation and enactment of an act of legislation that will protect donor-conceived children from all forms of discrimination within the larger society. Donor-conceived children should have all rights and privileges as the legal child of the infertile parents.

The enactment of such legislations may encourage honesty, openness, and the willingness to disclose the mode of conception and the identity of the sperm donor to children conceived using donor sperm in the region. Without such legislations and proper regulation, encouraging openness and sperm donor nonanonymity in Nigeria and in many developing countries may have disastrous consequence for everyone involved.

Being a hospital-based study is a limitation of the study as the respondents may not be a true representation of the entire infertile couples in the region.

\section{Disclosure}

The authors report no conflicts of interest in this work.

\section{References}

1. Gottlieb C, Lalos O, Lindblad F. Disclosure of donor insemination to the child: the impact of Swedish legislation on couples' attitudes. Hum Reprod. 2000;15(9):2052-2056.

2. Agarwal A, Mulgund A, Hamada A, Chyatte MR. A unique view on male infertility around the globe. Reprod Biol Endocrinol. 2015; $13: 37$.

3. Ikechebelu J, Adinma J, Orie E, Ikegwuonu S. High prevalence of male infertility in southeastern Nigeria. J Obstet Gynaecol. 2003;23(6): 657-659.

4. Frith L. Gamete donation and anonymity: the ethical and legal debate. Hum Reprod. 2001;16(5):818-824.

5. Polge C, Smith AU, Parkes AS. Revival of spermatozoa after vitrification and dehydration at low temperatures. Nature. 1949;164(4172):666.

6. Harper JC, Kennett D, Reisel D. The end of donor anonymity: how genetic testing is likely to drive anonymous gamete donation out of business. Hum Reprod. 2016;31(6):1135-1140. 
7. Human Fertilisation and Embryology Authority. Donor ConceptionBirths and Children. Available from: http://hfeaarchive.uksouth. cloudapp.azure.com/www.hfea.gov.uk/donor-conception-births.html. Accessed March 22, 2018.

8. Kirkman M, Rosenthal D, Johnson L. Families working it out: adolescents' views on communicating about donor-assisted conception. Hum Reprod. 2007;22(8):2318-2324.

9. Daniels KR, Grace VM, Gillett WR. Factors associated with parents' decisions to tell their adult offspring about the offspring's donor conception. Hum Reprod. 2011;26(10):2783-2790.

10. Owen L, Golombok S. Families created by assisted reproduction: parent-child relationships in late adolescence. J Adolesc. 2009;32(4): 835-848.

11. Sälevaara M, Suikkari AM, Söderström-Anttila V. Attitudes and disclosure decisions of Finnish parents with children conceived using donor sperm. Hum Reprod. 2013;28(10):2746-2754.

12. Pennings G. How to kill gamete donation: retrospective legislation and donor anonymity. Hum Reprod. 2012;27(10):2881-2885.

13. Allan S. Psycho-social, ethical and legal arguments for and against the retrospective release of information about donors to donor-conceived individuals in Australia. J Law Med. 2011;19(2):354-376.

14. McGee G, Brakman S-V, Gurmankin AD. Gamete donation and anonymity: disclosure to children conceived with donor gametes should not be optional. Hum Reprod. 2001;16(10):2033-2036.

15. Hahn SJ, Craft-Rosenberg M. The disclosure decisions of parents who conceive children using donor eggs. J Obstet Gynecol Neonatal Nurs. 2002;31(3):283-293.

16. Ugwu EO, Odoh GU, Obi SN, Ezugwu FO. Acceptability of artificial donor insemination among infertile couples in Enugu, southeastern Nigeria. Int J Womens Health. 2014;6(1):201-205.
17. Njikam Savage OM. Artificial donor insemination in Yaounde: some socio-cultural considerations. Soc Sci Med. 1992;35(7):907-913.

18. Araoye MO. Epidemiology of infertility: social problems of the infertile couples. West Afr J Med. 2003;22(2):190-196.

19. Ombelet W, Cooke I, Dyer S, Serour G, Devroey P. Infertility and the provision of infertility medical services in developing countries. Hum Reprod Update. 2008;14(6):605-621.

20. Daniels KR, Lewis GM, Gillett W. Telling donor insemination offspring about their conception: the nature of couples' decision-making. Soc Sci Med. 1995;40(9):1213-1220.

21. Mahlstedt PP, Greenfeld DA. Assisted reproductive technology with donor gametes: the need for patient preparation. Fertil Steril. 1989; 52(6):908-914

22. Feature N. Fertility on a shoestring. Nature. 2006;442:975-977.

23. Larsen U. Trends in infertility in Cameroon and Nigeria. Int Fam Plan Perspect. 1995;21(4):138-142.

24. Söderström-Anttila V, Sälevaara M, Suikkari AM. Increasing openness in oocyte donation families regarding disclosure over 15 years. Hum Reprod. 2010;25(10):2535-2542.

25. Blyth E, Landau R, editors. Third Party Assisted Conception across Cultures. London: Jessica Kingsley Publishers; 2004:148-167.

26. Clark B. A balancing act? The rights of donor-conceived children to know their biological origins. Georg J Int Comp Law. 2012;40(3):619-661.

27. Daniels KR. Information sharing in donor insemination: a conflict of rights and needs. Cambridge Q Healthc Ethics. 1995;4(2):217-224.
Patient Preference and Adherence

\section{Publish your work in this journal}

Patient Preference and Adherence is an international, peer-reviewed, open access journal that focuses on the growing importance of patient preference and adherence throughout the therapeutic continuum. Patient satisfaction, acceptability, quality of life, compliance, persistence and their role in developing new therapeutic modalities and compounds to optimize

\section{Dovepress}

clinical outcomes for existing disease states are major areas of interest for the journal. This journal has been accepted for indexing on PubMed Central. The manuscript management system is completely online and includes a very quick and fair peer-review system, which is all easy to use. Visit http://www. dovepress.com/testimonials.php to read real quotes from published authors. 